Rafael Cantón'

Pilar De Lucas Ramos ${ }^{2}$

Alejandra Garcia-Botella ${ }^{3}$

Alberto García-Lledó ${ }^{4}$

Javier Gómez-Pavón ${ }^{5}$

Juan González del Castillo ${ }^{6}$

Teresa Hernández-

Sampelayo ${ }^{7}$

Mari Cruz Martín-Delgado ${ }^{8}$

Francisco Javier Martín

Sánchez ${ }^{9}$

Manuel Martínez-Sellés ${ }^{10}$

José María Molero García ${ }^{11}$

Santiago Moreno Guillén ${ }^{12}$

Fernando Rodríguez-

Artalejo ${ }^{13}$

Julián Ruiz-Galiana ${ }^{14}$

Emilio Bouza ${ }^{15}$

\section{New variants of SARS-CoV-2}

\author{
${ }^{1}$ Servicio de Microbiología. Hospital Ramón y Cajal and Instituto Ramón y Cajal de Investigación Sanitaria (IRYCIS). Red \\ Española de Investigación en Patología Infecciosa (REIPI). Madrid. Spain. \\ ${ }^{2}$ Servicio de Neumología (Emeritus). Hospital General Universitario Gregorio Marañón, Universidad Complutense. \\ Madrid. Spain \\ ${ }^{3}$ Servicio de Cirugía General. Hospital Clínico Universitario de San Carlos. Universidad Complutense. Madrid. Spain \\ ${ }^{4}$ Servicio de Cardiología. Hospital Príncipe de Asturias. Universidad de Alcalá. Madrid. Spain \\ ${ }^{5}$ Servicio de Geriatría. Hospital Central de la Cruz-Roja. Universidad Alfonso X el Sabio. Madrid. Spain \\ ${ }^{6}$ Servicio de Urgencias. Hospital Clínico Universitario de San Carlos. Universidad Complutense. Madrid. Spain \\ ${ }^{7}$ Servicio de Pediatría y ACES. Hospital General Universitario Gregorio Marañón, Universidad Complutense. Madrid. \\ Spain \\ ${ }^{8}$ Servicio de Medicina Intensiva. Hospital de Torrejón. Universidad Francisco de Vitoria. Madrid. Spain \\ ${ }^{9}$ Servicio de Geriatría. Hospital Clínico Universitario de San Carlos. Universidad Complutense. Madrid. Spain \\ ${ }^{10}$ Servicio de Cardiología. Hospital General Universitario Gregorio Marañón, Universidad Europea. Madrid. Spain \\ ${ }^{11}$ Medicina de Familia. Enfermedades Infecciosas. Madrid. Spain \\ ${ }^{12}$ Servicio de Enfermedades Infecciosas. Hospital Universitario Ramón y Cajal. and Instituto Ramón y Cajal de \\ Investigación Sanitaria (IRYCIS). Universidad de Alcalá. Madrid. Spain \\ ${ }^{13}$ Departamento de Salud Pública. Universidad Autónoma de Madrid. Madrid. \\ ${ }^{14}$ Servicio de Medicina Interna. Hospital Ruber Internacional. Madrid. Spain \\ ${ }^{15}$ Servicio de Microbiología Clínica y Enfermedades Infecciosas (Emeritus, Comunidad de Madrid), Hospital General \\ Universitario Gregorio Marañón. CIBER de Enfermedades Respiratorias (CIBERES). Madrid. Spain
}

Article history

Received: 18 May 2021; Accepted: 23 May 2021; Published: 2 June 2021

\section{ABSTRACT}

The emergence and spread of new variants of SARS-CoV-2 has produced enormous interest due to their possible implication in the improved transmissibility of the virus, their consequences in the individual evolution of the infection, as well as in the possible escape from the immunity generated by the current vaccines. The variants that attract most attention are those of public health concern, including B.1.1.7 (UK), P.1 (Brazilian) and B.1.351 (South African). This list is extended by the variants of interest that emerge and are expanding in certain countries but are found sporadically in others, such as B.1.427 and B.1.429 (Californians) or B.1.617 (Indian). Whole genome sequencing or strategies specifically targeting the spicule gene are used in the microbiology laboratories for characterization and detection. The number of infected individuals, the sanitary situation of each country, epidemiological measures and vaccination strategies influence its dispersion and new variants are expected to emerge. This emergence can only be avoided today by increasing the vaccinated population in all countries and by not relaxing epidemiological containment measures. It is not excluded that in the future it will be necessary to revaccinate against new variants.

Keywords: COVID-19, viral variants, SARS-CoV2, vaccine resistance

Correspondence:

Emilio Bouza

Servicio de Microbiologia Clinica y Enfermedades Infecciosas del Hospital General

Universitario Gregorio Marañón, Universidad Complutense. CIBERES. Ciber de Enfermedades

Respiratorias. Madrid

E-mail:emilio.bouza@gmail.com

All authors belong to the Scientific Committee on COVID-19 of the Madrid College of Physicians (ICOMEM).
Nuevas variantes de SARS-CoV-2

\section{RESUMEN}

La emergencia y dispersión de las nuevas variantes de SARS-CoV-2 ha suscitado un enorme interés derivado de su posible implicación en la mayor transmisibilidad del virus, sus consecuencias en la evolución individual de la infección, así como en el posible escape a la inmunidad generada por las actuales vacunas. Las variantes que mayor atención deparan son las denominadas de preocupación o con importancia en Salud Publica, entre ellas la B.1.1.7 (británica), la P.1 (brasileña) y la B.1.351 (sudafricana). Esta lista se amplía con las variantes de interés que emergen y se encuentran en expansión en paises determinados pero que se encuentran de forma esporádica en otros, como la B.1.427 y B.1.429 (californianas) o B.1.617 (India). La secuenciación del genoma completo o estrategias dirigidas específicamente hacia el gen de la espícula se utilizan en los laboratorios de microbiología para su caracterización y detección. El número de individuos infectados, la situación sanitaria de cada pais, las medidas epidemiológicas y las estrategias de vacunación influyen en su dispersión siendo esperable que surjan nuevas variantes. Esta emergencia solo podrá evitarse hoy con el aumento de la población vacunada en todos los países y la no relajación de las medidas epidemiológicas de contención. No se descarta que en el futuro sea necesaria la revacunación frente a las nuevas variantes.

Palabras clave: COVID-19, variantes virales, SARS-CoV2, escape vacunal 


\section{INTRODUCTION}

The continuous development of mutations in the genome of SARS-CoV-2, the cause of the present pandemic, leads to the development of variants of the original Wuhan strain of the virus with small differences in its genetic structure but which may have more or less impact on the functional activity of the virus. There are variations in the genome of the virus which, due to their location or character, may pose a risk of greater transmissibility, greater virulence or less protection with current vaccines.

The monitoring of SARS-CoV-2 variants is occupying many people and microbiology laboratories throughout the world and, frequently, the information generated is slow to appear in traditional scientific publications due to the inherent editorial process that characterizes them.

The COVID Scientific Committee of the Illustrious College of Physicians of Madrid (ICOMEM), concerned about this situation, has attempted to review the information available on these variants and also to produce an opinion on their possible significance and future potential.

This document, structured in questions, attempts to provide the most recent information available on issues such as the nomenclature and definition of these variants, their study in the laboratory, their geographical distribution, the potential for easier transmission or their ability to cause more serious clinical pictures. Of particular concern is the risk that these variants could circumvent the protection established by currently available vaccines. The questions and answers are as follows:

\section{WHAT IS A SARS-COV-2 VARIANT? HOW ARE VARIANTS PRODUCED?}

A variant or lineage of SARS-CoV-2 is one that has mutations in its genome that confer modifications in its phenotype, e.g. different antigens, changes in transmissibility or virulence. Many of the variants described have competitive advantages over their ancestors and, in many cases, tend to be dominant.

SARS-CoV-2 variants arise naturally during replication, and the number of infected individuals is the major selection factor for these possible variants. It facilitates the persistence of those that evade the immune system, have a higher replication rate or are better transmitted [1]. Coronaviruses are RNA viruses and therefore should have a high mutation frequency. However, this frequency is reduced in SARS-CoV-2 by the presence of an enzyme that corrects errors during replication. The variants that have received the most scientific and clinical attention are those affecting the spike regions, since this is where the binding to ACE2 receptors occurs and can modify their clinical impact, as well as their ability to colonize the respiratory tract and the possibility of transmission [2]. For all these reasons, they are also relevant for Public Health [3].

In relation to the names given to the variants, in most cas- es they have taken the name of the country or geographical area in which they have been described, although this is not recommended. In this regard, the World Health Organization (WHO) has alerted of the geopolitical problems that could arise if this way of naming variants persists, and urges the use of names that refer to the phylogeny so that the new variants can be correlated with their ancestors [4]. Currently, although it is inevitable to refer to them by geographical origin, the most unanimously followed option is to use the "Pango" nomenclature system (acronym for Phylogenetic Assignment of Named Global Outbreak LINeages), and they should be named as Pango variant or lineage [5]. There are different bioinformatics solutions that facilitate the implementation of the Pango system (https://cov-lineages.org/) and repositories for the information (https://github.com/cov-lineages). One widely used is the Pangolin tool, which is referred to in many articles as the Pangolin nomenclature system. However, this name should be avoided because it can create confusion due to a possible origin related to an animal host and because it can be interpreted as a system different from Pango [6].

\section{WHAT IS MEANT BY VARIANTS OF INTEREST, VARIANTS OF PUBLIC HEALTH SIGNIFICANCE (VARIANTS OF CONCERN) AND VARIANTS OF HIGH CONSEQUENCE?}

From a public health point of view, the different variants of SARS-CoV-2 are grouped into three categories according to risk analysis: i) variants of interest (VOI), ii) variants of public health importance or variants of concern (VOC), and iii) variants of consequences [7].

i) Variants of interest (VOI) are often detected sporadically and in some countries after their initial description have been associated with a subsequent increase in cases. Many of the variants of interest have mutations in binding receptors that are important in variants of concern. These genetic changes suggest that they may be more contagious or may partially escape immunity conferred by natural infection or vaccination. These include variants P.2 (described in Brazil), B.1.526 (associated with rapid spread in New York), B.1.525 (known as Nigerian, but also initially described in the UK).

ii) Variants of public health importance or concern (VOC) are usually more contagious and generally more virulent than VOls as they may cause more severe disease with increased hospitalizations or higher mortality. They may reduce the efficacy of treatments and may escape the effect of antibodies acquired after natural infection with previous variants or by vaccination. Likewise, and within a low casuistry at a global level, cases of infections by these variants are usually described in patients who have already suffered COVID-19 (reinfections). This group includes variants B.1.1.7 (UK), B.1.351 (South African) and P.1 (Brazilian). They share between them some mutations in the sequence encoding the spike, for example, N501Y (in UK and South African) or E848K (in South African and Brazilian). In the case of the UK variant there is also a characteristic deletion (Y144 del) which has been used 
for recognition (surrogate marker) and laboratory follow-up. However, the WHO also attributes to these variants the difficulty of their detection in the laboratory and the decrease in the effectiveness of public health prevention and control measures [4]. It is thought that the N501Y and E848K mutations may confer SARS-CoV-2 adaptive advantages. Recently, the Centers for Disease Control and Prevention (CDC) in the United States has added two variants to the list of variants of concern, B.1.427 and B.1.429 (previously considered variant of concern) also called Californian. Both have the L452R and D614G mutation (Table 1).

iii) Finally, variants of high consequence are those that would cause more severe clinical manifestations. This category is only recognized by the CDC and would include variants associated with a real loss of preventive efficacy of vaccines and monoclonal antibody therapy. These could also include antiviral-resistant variants. For the time being, none of the SARSCoV-2 variants described have been classified in this category.

It should be noted that the European Center for Diseases and Prevention (ECDC), CDC or WHO may assign the labels "of interest" or "of concern" differently to the same variant depending on geographic location and spread. Also, the same variant may initially be classified as "of interest" and subsequently escalate to "of concern", while the opposite situation is also possible. In some cases, publications use the term variant under investigation in reference to new findings of variants that may be one-off observations or awaiting categorization as VOI or VOC. This group includes variant B.1.617. It was initially detected in India and subsequently in the United Kingdom and the United States. They include two mutations in the spicule, E4840 and L452R, so it has also been called "double mutant".

\section{WHAT ARE THE DIAGNOSTIC TOOLS AND STRATEGIES FOR LABELING VARIANTS?}

The identification and characterization of the different variants is performed using molecular biology tools and bioinformatics programs designed specifically for this purpose. Essentially, two strategies are employed. The first involves sequencing the complete genome of the virus, establishing the possible mutations or deletions of the variant by comparison with the strain initially sequenced from the first isolates in Wuhan (China). Special attention is paid to the spike-related region (S) as it defines the potential antigenic changes that confer uniqueness and may vary its transmissibility, pathogenicity, clinical significance and possible vaccine evasion. The sequencing process in the laboratory is very laborious due to the prior preparation of the sample, the retrotranscription (transfer of the RNA sequence to DNA), the generation of libraries (fragments to be sequenced) and the use of next generation sequencing (NGS) systems or devices, generally with Illumina or lon Torrent technologies. Once the sequences have been obtained, bioinformatics programs have been developed to assemble the fragments, detect known mutations and their combinations and label the sequenced strain. This strategy, by having the complete sequence of the virus, also allows a more in-depth analysis to be carried out later with bioinformatics programs that establish the phylogenetic relationship with its ancestors, the identification of additional mutations on already known variants or the possible emergence of new variants.

Once the sequence has been established and, if necessary, labeled with a name, this information is sent to the information systems of Public Health teams and the complete sequence with epidemiological information is usually shared on freely accessible web pages. The most widely used is $\mathrm{Gl}-$ SAID (https://www.gisaid.org/), acronym of Global Initiative on Sharing All Influenza Data, initially used for influenza and currently also for SARS-CoV-2. It is maintained with public and private funds.

A second strategy, which avoids complete sequencing of the SARS-CoV-2 genome, is to amplify only the regions of the gene responsible for the $S$ protein in which the mutations that define each of the variants are found. In this way, the variants are labeled by the eventual presence of these mutations. This strategy is widely used in variant-specific screening and for this purpose there are different commercial kits that target the regions of the $\mathrm{S}$ gene with the possible mutations. Also, laboratories with more experience tend to design their own strategy outside the commercial companies, designing specific primers to amplify the affected regions of the spicule gene and directly detect the mutations.

A special case has been the B.1.1.7 (UK) variant, characterized by a deletion (loss of nucleotides) in the spicule region [8]. B.1.1.7 presents a loss of positions 69 and 70 in this protein $(\Delta 69-70)$ in such a way that when trying to amplify this region with primers from the commercial house ThermoFisher TaqPath a negative result is produced. The absence of amplification of this region (SGTF marker, from S-gene target failure), but positive with other primers in two other regions, was the fact that alerted of its presence and has allowed its better traceability worldwide [9].

A drawback of the targeted amplification strategy of the spicule region is the possible presence of additional mutations, not contemplated in the targeted amplification schemes, so that strains could be labeled as known variants that in reality could constitute new variants. This situation has occurred with variant B.1.1.7 which has in some cases added the E484K mutation.

Screening is usually faster in obtaining results than full sequencing, which can take between 3 and 5 days depending on the automation of the different steps involved and the sequencers used.

\section{TO DATE, WHAT ARE THE MAIN CHARACTERISTICS (TRANSMISSIBILITY, GLOBAL SPREAD, REINFECTION CAPACITY, VACCINE RESISTANCE AND CLINICAL IMPACT) OF THE NEW VARIANTS?}

The number of variants and their description increases progressively as the number of sequenced isolates increases. 
Table 1 shows some of the characteristics of the variants that have had the greatest notoriety, either because of their worldwide dispersion due to their greater transmissibility or because of their foreseeable impact on possible vaccine failures.

UK or Bristish variant (B.1.1.7). In December 2020, the United Kingdom reported a new variant under investigation. It belongs to the B.1.1.7 lineage and presents as most important mutations when compared to Wuhan virus, two deletions, at positions 69-70 and $\mathrm{Y}_{144}$, and seven amino acid substitutions named N501Y, P681H, A540D, D614G, T716I, S982A and $\mathrm{D} 1118 \mathrm{H}$. These mutations affect the structure of the spike protein, in particular the N501Y mutation (a change from asparagine (N) to tyrosine (Y) at position 501) which is located in one of the contact residues of the $S$ protein with the ACE2 virus receptor, favoring its transmissibility [10].

Regarding the clinical impact, this variant does not appear to be associated with an increased risk of hospitalization or death, as confirmed by a prospective multicenter hospital study carried out in England [11] before the health care collapse. With a total of 496 patients admitted with positive PCR for SARSCoV-2, 58\% corresponded to the new variant, being younger patients and with less morbidity due to its greater community transmissibility but showing the same lethality by age group as
non-B.1.1.1.7. The study concludes that there is no association between severe disease and hospital death with lineage (B.1.1.7 vs non-B.1.1.7) even after analysis adjusted for hospital, age, sex, comorbidities, and race. The data also showed evidence of increased transmissibility associated with higher viral load (lower cycle threshold value). Preliminary analyses of the ECDC suggesting an increase in transmissibility of up to $70 \%$, which has made it dominant at present in most European countries, the USA and in some other countries such as Israel [12], are therefore confirmed. In this line, a study coordinated by the ECDC in seven countries of the European Union (Cyprus, Estonia, Finland, Ireland, Italy, Luxembourg, and Portugal) with the analysis of 19,995 cases caused by variants of concern and 3,348 cases not caused by these variants concludes that the risk of hospitalization and ICU admission with cases caused by variant B.1.1.7 was 1.7 and 2.3 times higher respectively (Table 1).

Variant B.1.1.7 shows no apparent increase in the rate of reinfection as it does not escape the antibodies of persons infected with the original variant of the virus, which have a greater ability to block the variant six months after infection compared to baseline [13]. Similarly, it is also susceptible to antibodies produced against the spicule by current vaccines both mRNA (Pfizer and Moderna) and non-replicating recombinant

\begin{tabular}{|c|c|c|c|c|c|c|}
\hline \multirow[t]{2}{*}{ Table 1} & \multicolumn{6}{|c|}{ Characteristics of the variants of concern and some of the variants of interes } \\
\hline & & $\begin{array}{c}\text { B.1.1.7 } \\
\text { (UK or Bristish) }\end{array}$ & $\begin{array}{c}\text { B.1.351 } \\
\text { (South African) }\end{array}$ & $\begin{array}{c}\text { P1 / P2 } \\
\text { (Brazilians) }\end{array}$ & $\begin{array}{c}\text { B.1.429/7 } \\
\text { (Californians) }\end{array}$ & $\begin{array}{c}\text { B.1.617.1 / } \\
\text { B.1.617.2/B.1.617.3 } \\
\text { (Indian) }\end{array}$ \\
\hline \multicolumn{2}{|c|}{ County of original description } & UK & South Africa & Brazil / Japan & California & India \\
\hline \multicolumn{2}{|c|}{ Relevant mutations in the spicule } & $\begin{array}{l}\text { N501Y, deletion 69-70, } \\
\text { deletion Y144, P681H, } \\
\text { A540D }\end{array}$ & $\begin{array}{c}\text { N501Y, E484K, K417N, } \\
\text { L18F, A701V }\end{array}$ & $\begin{array}{l}\text { N501Y, E484K, K417T / } \\
\text { E484K, D614G, V1176F }\end{array}$ & L452R, W152C, S13I & E484Q, L452R, P681R \\
\hline \multicolumn{2}{|c|}{ Estimated transmissibility } & $50-70 \%$ increased & Not increased & $\begin{array}{l}\text { Increased \% not yet } \\
\text { stablished }\end{array}$ & $20 \%$ increased & $\begin{array}{l}\text { Increased } \% \text { not yet } \\
\text { stablished }\end{array}$ \\
\hline \multicolumn{2}{|c|}{ Risk of hospitalization } & 1.7 increased & 3.6 increased & $\begin{array}{l}2.6 \text { increased } \\
\text { (P.1 variant) }\end{array}$ & $?$ & $?$ \\
\hline \multicolumn{2}{|c|}{ Risk of admittance in the intensive care unit } & 2.3 increased & 3.3 increased & 2.2 increased & $?$ & $?$ \\
\hline \multicolumn{2}{|l|}{ Mortality } & No mayor & $?$ & $?$ & $?$ & $?$ \\
\hline \multicolumn{2}{|c|}{ Escape to the immune response } & NO & YES & $\begin{array}{l}\text { YES (lower than } \\
\text { B.1.351) }\end{array}$ & $\begin{array}{c}\text { YES (lower than } \\
\text { B.1.351) }\end{array}$ & YES \\
\hline \multicolumn{2}{|c|}{ Vaccination effectiveness } & YES & $\begin{array}{l}\text { Significant reduction } \\
\text { of the effectivity of } \\
\text { Novartis, Janssen and } \\
\text { AstraZeneca vaccines } \\
\text { (neutralized with } \\
\text { serum from mRNA } \\
\text { vaccinated individual) }\end{array}$ & $\begin{array}{c}? \\
\text { Few studies. } \\
\text { mRNA vaccines } \\
\text { neutralize P.1 }\end{array}$ & $\begin{array}{c}\text { Few studies } \\
\text { (neutralized with } \\
\text { serum from mRNA } \\
\text { vaccinated individual) }\end{array}$ & $?$ \\
\hline \multicolumn{2}{|c|}{ Situation in Spain } & $\begin{array}{l}\text { Predominant } \\
\text { (79.5-99.5\%) }\end{array}$ & $\begin{array}{c}\text { Very low frequency } \\
\qquad(1.2 \%)\end{array}$ & $\begin{array}{l}\text { Very low frequency } \\
\qquad(1-4 \%)\end{array}$ & $\begin{array}{l}\text { Very low frequency } \\
\qquad(<1 \%)\end{array}$ & $?$ \\
\hline
\end{tabular}


viral vector (AstraZeneca, Janssen) [14]. The SIREN study, a cohort of 23,324 healthcare workers aged 18 years or older from all UK public hospitals vaccinated with the BNT162b2 mRNA vaccine (Pfizer), conducted when variant B.1.1.7 was predominant, showed that it prevented both symptomatic and asymptomatic infection (85\% effectiveness after 7 days of the second dose) contributing to decreased transmission of infection, covering both the original SARS-CoV 2 and the variant [15].

South African variant (B.1.351). South Africa announced in December 2020 a new variant, named as 501Y.V2 (B.1.351). The variant also binds more readily to human cells due to three mutations in the receptor-binding domain in the S-protein glycoprotein of the virus spicule, including N501Y, a mutation also presents in variant B.1.1.7 but different according to phylogenetic analysis [16]. It is predominant in South Africa and neighboring countries and with progressive increase in European countries (especially in the Tyrol region of Austria, Germany, Belgium, and France) [17]. Regarding its clinical impact, the data are not as clear as in the UK variant. Most studies to date seem to show that it lacks increased infectivity, but does have immunologic escape $[10,18]$ from the acquired immune response following natural infection. In addition, it has been found in clinical trials that the protective efficacy of Novartis, Janssen and AstraZeneca vaccines has significantly decreased in South Africa, where this variant was prevalent [19].

In different serological studies, a reduction in both the titers of antibodies against the protein $S$ receptor binding domain and neutralizing antibodies for the B.1.351 variant compared to non-B.1351 is observed. However, most acute and convalescent patient sera from infected and vaccinated individuals neutralize this variant, suggesting that protective immunity against SARS-CoV-2 is retained [20]. In this regard, a study with the Pfizer vaccine (BNT162b2 vaccine) has recently been published showing neutralization in serum of both the South African and Brazilian variants (P.1) after the second dose [21]. According to the previous multicenter study conducted by the ECDC, this variant is the one with the highest risk of hospitalization (3.6 times higher) and ICU admission (3.3 times higher) (Table 1).

Brazilian variant (P.1 or B.1.1.28.1). It is considered a $\mathrm{VOI}$ or $\mathrm{VOC}$ depending on the agencies or countries. It belongs to the B.1.1.28.1 lineage and has 17 nonsynonymous mutations: L18F, T20N, P26S, D138Y, R190S, K417T, E484K, N501Y, D614G, H655Y, T1027l and V1176F in protein S; S1188L, K17950, E5665D in ORF1ab; E92K in ORF8; and P80K in protein N. It also has one deletion (SGF 3675-3677 in ORF1ab) and 4 synonymous mutations. P.1 is the SARS-CoV-2 variant with the most accumulated mutations in the $S$ protein (12 mutations), some of them shared with the UK and South African strains (N501Y) and others shared only with the South African strain (L18F, K417T, E484K, D614G), which have important implications for transmissibility, reinfection rates and evasion of antibody-mediated immunity. Cases of reinfection associated with this variant have been reported. It was first identified in January 2021 in travelers from Japan coming from Brazil (Manaus region). This variant has a confirmed presence in at least 21 countries. A study in Manaus (Brazil) has estimated transmissibility between 1.4 and 2.2 times higher than previous variants and is associated with a 1.1-1.8 higher mortality risk, although this figure may be biased by the saturation of the health system. In this regard, the recent ECDC study confirms the increased risk of hospitalization (2.6 times higher) and ICU admission (2.2 times higher). No data are available on the efficacy of vaccines developed or under development against this variant, but a similar impact to that of B.1.351 (South African variant) is presumed. The Manaus study estimates that $25-61 \%$ of cases may have evaded the immune system and has a moderate impact on the efficacy of monoclonal antibodies [22, 23]. It could also moderately decrease the efficacy of antibodies generated by previous infection with the wild-type SARSCoV-2 strain or by current vaccines against COVID-19. Given the high number of genetic events in the Brazilian variant, it is possible and likely that the ability of vaccines against P.1 will be diminished in terms of sterilizing immunity. However, the ability to contain infection progression, severe manifestations and deaths, dependent on cell-mediated immunity, might be less affected, in which case vaccines would still be useful [24]. It has been shown that CD4+ and CD8+ T-cell responses are not affected with this variant. A separate case would be the Brazilian P-2 variant. It was originally detected in Brazil (Rio de Janeiro) with cases already present in other countries, related to travel. Monoclonal antibodies developed with other strains have a lower capacity to neutralize this $\mathrm{P}-2$ variant and a reduction in neutralization by convalescent and post-vaccination sera has also been observed. It also has the E484K mutation.

Californian variants (B.1.427 y B.1.429). These are two variants first identified in February 2021 in California that were classified by the CDC as VOC in March 2021 [25] although in Spain they remain as variants of interest. They have an increased transmissibility (approximately 20\%) with a significant impact on neutralization by some treatments classified by the FDA as EUA (emergency authorization use), but not all. A moderate reduction in neutralization has been demonstrated when using convalescent and post-vaccination sera.

Indian Variant (B.1.617). It was initially described in India in October 2020 and has been reported in more than 20 countries. It was initially also known as a "double mutant" as it has two mutations (E4840 and L452R) in the sequence of protein $\mathrm{S}$. This name is being challenged as it has at least 11 other mutations. One of them, the P681R mutation, will give it, like the two previous ones, a greater pathogenic potential since it affects its affinity for the ACE2 receptor. It would also have a greater capacity to evade the immune system than other variants [26]. However, preliminary data suggest that it does not evade the action of the Indian-made Covaxin vaccine based on virus inactivation [27].

To date, three sublineages B.1.617.1, B.1.617.2 and B.1.617.3 have been described. They have additional mutations, but not all share the same mutations, including some 
that would define them as double mutants (B.1.617.2 does not have the E4840 mutation). It should be noted that the mutation at position 484 (E484G in the Indian variant) is also present in other variants, but with different changes (E484K in the South African, Brazilian and Californian variants) demonstrating the relevance of this position. The L452R mutation is present among others in the California variants (B.1.427 and B.1.429) and the P681R in the UK variant (B.1.1.7).

At the moment it is difficult to contrast information on its clinical significance, although with the inherent reservations, its wide progression and diffusion in India and the high mortality of COVID-19 in this country, would indicate a wide transmission capacity and a major pathogenic effect.

\section{WHAT IS THE PREVALENCE OF THE DIFFERENT VARIANTS IN SPAIN AT THE PRESENT TIME?}

The evolution of the different variants in Spain can be followed in the periodic epidemiological reports provided by the Ministry of Health [12]. The last published report considers the UK (B.1.1.7), South African (B.1.351) and Brazilian (P.1) as variants of concern (VOC) and those of Rio de Janeiro (P.2), Nigeria (B.1.525), California (B.1.427/B.1.429), New York (B.1.526), Uganda (A.23 .1), India (B.1.617), Colombia (B.1.621) and the UK variant with the E484K mutation as variants of interest (VOI) [28]. For the latter, there are still no data that allow us to know the impact they will have in Spain from the point of view of Public Health.

The UK variant, belonging to the B.1.1.7 lineage, was detected in Spain for the first time in mid-December in the Community of Madrid and since then its presence has grown exponentially, until it is currently the dominant variant. According to the latest epidemiological update data estimated by SGTF marker or specific PCR N501Y, the UK variant exceeds 90\% of national isolates, with figures ranging from $82.6 \%$ in Murcia to $99.5 \%$ in Asturias. In the Community of Madrid it reaches $90.6 \%$. This undoubtedly reflects its greater contagiousness.

The South African variant, B.1.351, was reported on December 18, 2020. Currently, the latest data from the Spanish Ministry of Health report an incidence of $0.3 \%$. Only $15 \%$ of cases have a history of travel to Africa.

The Brazilian variant P.1 was reported for the first time in Spain at the beginning of February in the Community of Madrid. As in the case of the South African variant, 85\% are not linked to direct travel to Brazil or another American country. The centralized data do not represent all the autonomous communities and with these the incidence of both variants evaluated by PCR detection of the regions of the spicule where the mutations that define them are found, are between 0.3 and $3.8 \%$.

The Nigerian variant, B1.525, of which 41 non-travel-related cases have already been reported, is also increasing. The Spanish Ministry of Health has also considered of epidemiological interest the Californian variant, B.1.429, with 26 cases,
4 sporadic and the rest associated with 3 different outbreaks. Of the Rio de Janeiro (P2) variant, 14 cases have been reported, two in travelers from Brazil, 9 in a hospital outbreak with no geographic links and another 3 in family outbreaks. There have also been 8 cases of variant B.1.526 from New York, 3 of A.23.1 from Uganda, 1 of the E484K mutation from the UK and 1 of C.16 from Portugal. This last report also includes some cases of the Indian variant B.1.617, linked to outbreaks in subjects from this country and of the Colombian variant B.1.621, also related to travelers.

The reliability of variant detection is logically linked to the sequencing rate of microbiology laboratories. The Ministry published on February 22, 2021 the "Document for the Integration of Genomic Sequencing for SARS-Cov2 Surveillance" which set a sequencing target for 1-2\% of samples [29]. Consultation of the GISAID registry shows that Spain shares many sequences in this registry and that they correspond to $0.67 \%$ of the total number of cases (https://www.gisaid.org/). Howev$\mathrm{er}$, the situation is constantly changing so that the figures are modified every week.

\section{WHY DO SOME VARIANTS SPREAD AROUND THE WORLD MUCH MORE THAN OTHERS? WHAT ARE THE SELECTION FACTORS FOR THESE VARIANTS?}

The new variants can spread because they have a competitive advantage over the original strains. The most important is higher infectivity, resulting from higher viral load in respiratory mucosa, longer duration of infection, better affinity for virus cell receptors on mucosal cells, etc. Another competitive advantage is loss of virulence, which relatively increases mild and asymptomatic infections that are more difficult to detect and, thus, facilitates transmission. A plausible hypothesis is that the greater infectivity of the UK strain (B.1.1.7) has made it more difficult for other possibly less transmissible but more severe strains, such as the South African strain, to spread throughout the world. However, the greater transmissibility of the UK strain (without the need for greater severity) has resulted in an increase in the total number of infections, including severe forms leading to hospitalization and death.

In addition, poor immune response to either natural infection or vaccine facilitates the selection of dangerous variants. Indeed, a high virus replication capacity (leading to high viral load and high infectivity) together with a suboptimal level of neutralizing antibodies (e.g., in immunocompromised patients) are the ideal medium for variants to emerge and spread rapidly $[30,31]$. All this is a powerful argument for vaccinating as many people as possible in the shortest possible time with highly effective vaccines, and especially with those requiring a single dose [32]. This is also why, in vaccines requiring two doses, the time period between doses should not be excessively increased, as partial immunity in that period may facilitate the selection of vaccine-resistant strains. 


\section{ARE NEW VARIANTS TO BE EXPECTED OVER THE COURSE OF THE EPIDEMIC, AND ARE NEW VARIANTS LIKELY TO PRODUCE MORE REINFECTIONS OR ESCAPE VACCINES?}

It is likely that there will be more variants throughout the epidemic [33]. In fact, the virus's own mutational capacity has generated many new variants since January 2020. Most of the new variants will be irrelevant to the course of the epidemic, because they will not have many competitive advantages over the existing ones. However, it cannot be ruled out that some may facilitate reinfection, especially in immunocompromised individuals, chronically ill patients with poor immune status or those with a poor response to vaccination. On the other hand, the extension of vaccination itself may also select the most resistant variants, which may facilitate vaccine escape in the community.

\section{WHAT KIND OF EVIDENCE IS THERE TO SUGGEST WHETHER A VARIANT CAN ESCAPE VACCINE PROTECTION?}

There are several types of evidence. First, in vitro studies are carried out with serum samples from vaccinated individuals to analyze whether the neutralizing capacity of the antibodies generated by the vaccine is progressively reduced with new variants of the virus with respect to the initial strains that were predominant in those places where the vaccine was evaluated. For example, the B.1.351 variant initially identified in South Africa is known to be partially resistant to antibodies generated by mRNA vaccines, and the neutralizing antibodies generated by the AstraZeneca vaccine have little activity against this variant. However, the level of antibody that guarantees sufficient vaccine protection is uncertain, while protection also depends on vaccine-induced cell-mediated immunity; therefore, these studies provide only indirect evidence that some vaccine escape is possible.

In addition, the virus load in the respiratory tract of the (few) vaccinees who end up suffering from COVID-19 can be analyzed. A higher viral load with the new variants than with the original strain probably suggests some vaccine escape.

Also, multicenter clinical trials conducted in several countries can compare vaccine efficacy in territories where the new variants have spread with that observed in territories where the original strain predominates. For example, in the pivotal trial of the Janssen vaccine [34], efficacy was somewhat lower in South Africa (where the B.1.351 variant was emerging) than in the United States, where this variant was very rare. It has also been shown that the AstraZeneca vaccine is not effective in reducing the risk of mild SARS-CoV-2 infection in people in South Africa [35].

The most important, albeit late, evidence is the loss of vaccine effectiveness (especially with severe forms of the disease) in real-life studies, either in populations in which vaccination is being implemented (e.g., lower than expected reduction in severe COVID-19 cases, or hospitalized, ICU admissions etc.) or in populations that received the vaccine months ago and maintain high levels of vaccine-generated antibodies (e.g., increased infections months after vaccination). Fortunately, no real-life studies suggest that relevant vaccine escape has occurred; although vaccine effectiveness needs to be monitored over time, this is the case in Israel, the United Kingdom or the United States of America, where many vaccines have been administered, On the other hand, vaccine escape is not usually an all/nothing phenomenon. In the short term, it is not considered likely that current vaccines could be totally useless, and among the undesirable scenarios, the most likely would only be that of some reduction in vaccine effectiveness.

\section{IS IT POSSIBLE TO DEVELOP EFFECTIVE VACCINES FOR EACH NEW VARIANT IN A SHORT PERIOD OF TIME? IS THERE ANY TYPE OF VACCINE OR VACCINATION STRATEGY THAT CAN DEFEND US AGAINST MOST OF THE VARIANTS THAT MAY APPEAR? WILL WE NEED TO BE PERIODICALLY REVACCINATED AGAINST COVID-19?}

Given the possibility of the emergence of new SARS-CoV-2 variants less sensitive to the protection conferred by vaccines currently in use or in the process of approval, the production of new vaccines adapted to the new antigens is proposed. Even at the present time, if variants with lower sensitivity to protection from available vaccines, as could occur with the South African and Brazilian variants, become widespread, it would probably be necessary to repurpose available vaccines. This may even need to be done on a regular basis, as with influenza virus vaccines [36].

All developers of current vaccines have announced that they are already working on new developments to cover possible new variants that circumvent the immune response of the developed vaccines. The options are diverse: 1) replacing the RNA of the mRNA vaccines or the DNA of the viral vector vaccines, which are currently constructed from the original Wuhan SARS-CoV-2 strains; 2) adding new components to the current ones; 3 ) testing booster doses with the current vaccines; and 4) redesigning the vaccines seeking greater potentiation of cell-mediated immunity [37].

Aware of the need created, the European Medicines Agency (EMA) has considered it an urgent public health priority to define an accelerated regulatory process for the adaptation of vaccines to protect against current or future variants. In this regard, the EMA's Committee for Human Medicinal Products (CHMP) has adopted a discussion paper detailing the laboratory, clinical, quality and manufacturing data necessary to support the approval of such second-generation vaccines [38]. The assumption behind the CHMP guidelines is that a new vaccine variant would rely largely on the same technology and platform as the "mother" vaccine, a vaccine already approved in the EU for the prevention of COVID-19. The difference would be in the specific structure (antigen) selected to trigger the immune response in individuals who undergo the new vaccine. 


\section{WHAT MEASURES CAN INDIVIDUALS OR HEALTH AUTHORITIES TAKE TO REDUCE THE SPREAD OF NEW AND EMERGING VARIANTS?}

The available information indicates that the most important factor conditioning the selection and dissemination of new variants is the increase in the number of people infected with SARS-COV-2. Measures to reduce virus transmission should also reduce the spread of new variants, including the most transmissible ones.

The emergence and spread of new variants is a problem of epidemiological, clinical, health and social importance, as described in this document. Its control is complicated due to the differences between countries and is conditioned by multiple factors that change over time, such as the infected population, the prevention measures applied, epidemiological surveillance, diagnostic tests performed, identification strategies, the effect exerted by vaccines, etc.

The ECDC has assessed the current situation and concludes that the probability of introduction of new variants of SARS-COV-2 in the EU and Member States, and the displacement of those already circulating, is very high and the impact it may have is also high. Specifically, it indicates that the risk of introduction and community spread of new variants of concern is high or very high. More than 3 months ago, the ECDC warned of the need to prepare for the rapid rise of new variants, to organize to protect the capacity of health systems and to accelerate vaccination campaigns [39]. Recommendations for prevention at both the collective and individual levels are based on the following points:

1. Surveillance, diagnostic testing, sequencing and detection of emerging variants. The key is that this should be done in real time, which may allow public health measures to be taken to reduce the potential impact of new variants on the population. Results should be communicated to public health authorities and rapidly shared in established alert and surveillance programs (EWRS, and TESSY) [39]. It is recommended that microbiology laboratories be prepared, staffed and trained to perform the required studies.

Likewise, early detection and follow-up of patients infected by the new variants, as well as their contacts before and after diagnosis, is very important. This strategy is essential in order to have accurate information on the situation of community transmission and its evolution.

2. Application of non-drug individual protection measures (NPIs). Given that in the coming months not all the European population will be vaccinated, it is recommended not to relax indiscriminately the individual protection measures while there is a high level of community transmission.

3. Maintain, in educational centers, the current preventive measures until it is possible to vaccinate students or until community transmission is very low.

4. To curb the importation and spread of new variants, the ECDC recommends avoiding unnecessary travel, restricting travel by infected persons, and strict compliance with imposed preventive measures. Also, travel and receipt of travelers from highly endemic areas can be limited [40].

5.Recommendation to accelerate as much as possible the pace of vaccination in at-risk populations, the elderly and health care workers. Monitor vaccine efficacy for new variants and study infections attributed to vaccine escapes.

\section{CAN UNIVERSAL VACCINATION REDUCE THE RISK OF CIRCULATION OF NEW VARIANTS?}

The hoarding of vaccines in some countries and the delay of vaccination in less developed countries is not only ethically unacceptable, but may allow the development of variants that recirculate in countries already vaccinated and perpetuate the pandemic. For these reasons, the term "vaccine nationalism" has been coined, against which the WHO warns [41]. It is necessary to be aware of and support initiatives for universal vaccination such as the COVID-19 Tool Access Accelerator [42] and the GAVI alliance for vaccination [43], which manage the COVAX tool. The possibility of variant emergence in non-vaccinated countries is one more reason to subscribe to the statement that "no one is safe until we are all safe" [44].

\section{CONCLUSIONS}

1.- SARS-CoV-2 variants or lineages arise from modifications (mutations or deletions) in its genome, with the high number of infected individuals being the major selection factor. It is therefore important to reduce this number by monitoring epidemiological measures and vaccination programs.

2.- The detection of variants is generally carried out by means of two different but complementary strategies, using molecular biology techniques and bioinformatics programs. The first is directed specifically against the $S$ gene to recognize known mutations or deletions and the second by sequencing the complete SARS-CoV-2 genome.

3.- The most important variants are those that have mutations in the spicule gene (S gene) and that phenotypically affect binding to the ACE2 receptor.

4.- From a Public Health point of view, variants are classified into variants under investigation, variants of interest and variants of concern. The latter have a lower clearance rate, greater transmissibility, can escape to a greater or lesser extent the immunity conferred by natural immunity or vaccination, with an increased risk of hospitalization and admission to the ICU and, in some cases, may have greater lethality.

5.- In Spain, at present, the variants of concern are B.1.1.7 (UK), P.1 (Brazilian) and B.1.351 (South African). The UK variant has progressively increased since its initial detection in December 2020, reaching figures that in some Autonomous Communities in Spain account for more than 
95\% of cases. The Brazilian and South African variants range between $0.3 \%$ and $4 \%$.

6.- The higher infectivity of the variants of concern is a consequence of a higher viral load during infection and a possible lower response of the immune system.

7.- The number of infected individuals, the health situation in each country, epidemiological measures and vaccination strategies influence the spread of variants, and new lineages are expected to emerge in the future if the pandemic is not controlled.

8.- At present, the emergence of new variants can only be reduced by increasing the vaccinated population in all countries and by not relaxing epidemiological containment measures.

9.- It cannot be ruled out that revaccination against new variants will be necessary in the future, so it will be necessary to increase the manufacturing, distribution, and administration capacity of these vaccines.

10.- Both basic and clinical research should be increased, to learn about the pathogenic aspects of the new variants, and clinical research to assess their real impact.

\section{FUNDING}

None to declare

\section{CONFLICTS OF INTEREST}

The authors declare that they have no conflicts of interest.

\section{REFERENCES}

1. Fauver JR, Petrone ME, Hodcroft EB, Shioda K, Ehrlich HY, Watts $A G$, et al. Coast-to-coast spread of SARS-CoV-2 in the United States revealed by genomic epidemiology. medRxiv. 2020. DOI: 10.1101/2020.03.25.20043828.

2. Lauring AS, Hodcroft EB. Genetic Variants of SARS-CoV-2-What Do They Mean? Jama. 2021. DOI: 10.1001/jama.2020.27124.

3. Wyllie AL, Vogels $C B F$, Grubaugh ND. Saliva for Detection of SARS-CoV-2. Reply. N Engl J Med. 2021;384(9). DOI: 10.1056/NEJMc2032165.

4. Abbasi K. Covid-19: Social murder, they wrote-elected, unaccountable, and unrepentant. Bmj. 2021;372:n314. DOI: 10.1136/bmj. n314.

5. Andersen KG, Rambaut A, Lipkin WI, Holmes EC, Garry RF. The proximal origin of SARS-CoV-2. Nat Med. 2020;26(4):450-2. DOI: 10.1038/s41591-020-0820-9.

6. Rambaut A, Holmes EC, O'Toole Á, Hill V, McCrone JT, Ruis C, et al. Addendum: A dynamic nomenclature proposal for SARSCoV-2 lineages to assist genomic epidemiology. Nat Microbiol. 2021;6(3):415. DOI: 10.1038/s41564-021-00872-5.

7. Recommendations for Prevention and Control of Influenza in
Children, 2020-2021. Pediatrics. 2020. DOI: 10.1542/peds.2020024588.

8. Rambaut A, Loman N, Pybus O, Barclay W, Barrett J, al. e. Preliminary genomic characterisation of an emergent SARS-CoV-2 lineage in the UK defined by a novel set of spike mutations. Descargado de https://virologicalorg/t/preliminary-genomic-characterisation-ofan-emergent-sars-cov-2-lineage-in-the-uk-defined-by-a-novelset-of-spike-mutations/563 2020;Accessed May 1, 2020.

9. Bal A, Destras G, Gaymard A, Stefic K, Marlet J, Eymieux S, et al. Two-step strategy for the identification of SARS-CoV-2 variant of concern 202012/01 and other variants with spike deletion H69-V70, France, August to December 2020. Euro Surveill. 2021;26(3). DOI: 10.2807/1560-7917.Es.2021.26.3.2100008.

10. Hoffmann M, Arora P, Groß R, Seidel A, Hörnich BF, Hahn AS, et al. SARS-CoV-2 variants B.1.351 and P.1 escape from neutralizing antibodies. Cell. 2021. D0I: 10.1016/j.cell.2021.03.036.

11. Frampton D, Rampling $T$, Cross A, Bailey H, Heaney J, Byott M, et al. Genomic characteristics and clinical effect of the emergent SARSCoV-2 B.1.1.7 lineage in London, UK: a whole-genome sequencing and hospital-based cohort study. Lancet Infect Dis. 2021. D0I: 10.1016/s1473-3099(21)00170-5

12. Sanidad. Md. Actualización de la situación epidemiológica de las variantes de SARS-CoV-2 de importancia en salud pública en España. 2021. Descargado de: https://wwwmscbsgobes/profesionales/saludPublica/ccayes/alertasActual/nCov/documentos/COVID19_Actualizacion_variantes_20210426pdf..

13. Planas D, Bruel T, Grzelak L, Guivel-Benhassine F, Staropoli I, Porrot $F_{\text {, et }}$ al. Sensitivity of infectious SARS-CoV-2 B.1.1.7 and B.1.351 variants to neutralizing antibodies. Nat Med. 2021. DOI: 10.1038/ s41591-021-01318-5.

14. Bian L, Gao F, Zhang J, He Q, Mao Q, Xu M, et al. Effects of SARSCoV-2 variants on vaccine efficacy and response strategies. . Expert Rev Vaccines 2021;Epub ahead of print. PMID: 33851875; PMCID: PMC8054487.:1-9. DOI: 10.1080/14760584.2021.1903879.

15. Hall VJ, Foulkes $S$, Saei A, Andrews N, Oguti B, Charlett A, et al. COVID-19 vaccine coverage in health-care workers in England and effectiveness of BNT162b2 mRNA vaccine against infection (SIREN): a prospective, multicentre, cohort study. Lancet. 2021. DOI: 10.1016/s0140-6736(21)00790-x.

16. Sanidad Md. Evaluación rápida de riesgo. Circulación de variantes de SARS-CoV-2 de interés para la salud pública en España. Actualización 4 de marzo 2021. Consultado 18 de abril de 2021. Disponible en: https://wwwmscbsgobes/profesionales/saludPublica/ccayes/ alertasActual/nCov/documentos/20210304-EERpdf.

17. Ministerio de Sanidad, Sanitarias. CdCdAyE. Actualización de la situación epidemiológica de las variantes de SARS-CoV-2 de importancia en salud pública en España. 2021. Disponible en: https://wwwmscbsgobes/profesionales/saludPublica/ccayes/alertasActual/nCov/documentos/COVID19_Actualizacion_variantes_20210412pdf.

18. Zhou D, Dejnirattisai W, Supasa P, Liu C, Mentzer AJ, Ginn HM, et al. Evidence of escape of SARS-CoV-2 variant B.1.351 from natural and vaccine-induced sera. Cell. 2021. DOI: 10.1016/j.cell.2021.02.037 
19. Madhi SA, Baillie V, Cutland CL, Voysey M, Koen AL, Fairlie L, et al. Efficacy of the ChAdOx1 nCoV-19 Covid-19 Vaccine against the B.1.351 Variant. N Engl J Med. 2021. DOI: 10.1056/NEJMoa2102214

20. Edara W, Norwood C, Floyd K, Lai L, Davis-Gardner ME, Hudson $W H$, et al. Infection- and vaccine-induced antibody binding and neutralization of the B.1.351 SARS-CoV-2 variant. Cell Host Microbe. 2021;29(4):516-21.e3. DOI: 10.1016/j.chom.2021.03.009

21. Liu $Y$, Liu J, Xia $H$, Zhang $X$, Fontes-Garfias CR, Swanson $K A$, et al. Neutralizing Activity of BNT162b2-Elicited Serum. N Engl J Med. 2021. DOI: 10.1056/NEJMc2102017

22. Anónimo. Genomic Characterisation of an Emergent SARS-CoV-2 Lineage in Manaus: Preliminary Findings - SARS-CoV-2 Coronavirus / NCoV-2019 Genomic Epidemiology. Disponbible en: https://virologicalorg/t/genomic-characterisation-of-an-emergent-sars-cov-2- lineage-in-manaus-preliminary-findings/586. 2021.

23. Sabino EC, Buss LF, Carvalho MPS, Prete CA, Jr., Crispim MAE, Fraiji NA, et al. Resurgence of COVID-19 in Manaus, Brazil, despite high seroprevalence. Lancet. 2021;397(10273):452-5. DOI: 10.1016/ s0140-6736(21)00183-5

24. Buss LF, Prete CA, Jr., Abrahim CMM, Mendrone A, Jr., Salomon T, de

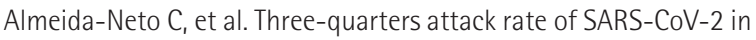
the Brazilian Amazon during a largely unmitigated epidemic. Science. 2021;371(6526):288-92. DOI: 10.1126/science.abe9728

25. Deng $X$, Garcia-Knight MA, Khalid MM ea. Transmission, infectivity, and antibody neutralization of an emerging SARS-CoV-2 variant in California carrying a L452R spike protein mutation. . MedRxiv 2021 2021;doi: https://doi.org/10.11/2021.03.07.21252647.

26. Starr TN, Greaney AJ, Dingens AS, Bloom JD. Complete map of SARS-CoV-2 RBD mutations that escape the monoclonal antibody LY-CoV555 and its cocktail with LY-CoV016. Cell Rep Med. 2021;2(4):100255. DOI: 10.1016/j.xcrm.2021.100255

27. Yadav PD, Sapkal GN, Abraham P, Ella R, Deshpande G, Patil DY, et al. Neutralization of variant under investigation B.1.617 with sera of BBV152 vaccinees. BioRxyv. 2021. DOI: https://doi. org/10.1101/2021.04.23.441101

28. Sanidad Md. Actualización de la situación epidemiológica de las variantes de SARS-CoV-2 de importancia en Salud Pública de SARS-CoV-2 en España. . (Disponible en https://wwwmscbsgobes/ profesionales/saludPublica/ccayes/alertasActual/nCov/documentos/COVID19_Actualizacion_variantes_2021 0504pdf). 2021.

29. Sanidad Md. Integración de la secuenciación genómica en la vigilancia del SARS-CoV-2. Descargado de https://wwwmscbsgobes/ profesionales/saludPublica/ccayes/alertasActual/nCov/documentos/Integracion_de_la_secuenciacion_genomica-en_la_vigilancia_del_SARS-CoV-2pdf. 2021.

30. Kemp SA, Collier DA, Datir RP, Ferreira I, Gayed $S$, Jahun A, et al. SARS-CoV-2 evolution during treatment of chronic infection. Nature. 2021;592(7853):277-82. DOI: 10.1038/s41586-021-03291-y

31. Creech CB, Walker SC, Samuels RJ. SARS-CoV-2 Vaccines. Jama. 2021. DOI: $10.1001 /$ jama.2021.3199

32. Moore JP. Approaches for Optimal Use of Different COVID-19 Vaccines: Issues of Viral Variants and Vaccine Efficacy. Jama. 2021. DOI: 10.1001/jama.2021.3465.
33. Rubin R. COVID-19 Vaccines vs Variants-Determining How Much Immunity Is Enough. Jama. 2021. DOI: 10.1001/jama.2021.3370.

34. Sadoff J, Le Gars M, Shukarev G, Heerwegh D, Truyers C, de Groot AM, et al. Interim Results of a Phase 1-2a Trial of Ad26.COV2.S Covid-19 Vaccine. N Engl J Med. 2021. DOI: 10.1056/NEJMoa2034201

35. Madhi SA, Baillie $V$, Cutland $C L$, al. e. Safety and efficacy of the ChAd0x1 nCoV-19 (AZD1222) Covid-19 vaccine against the B.1.351 variant in South Africa. medRxiv Published online February 12, 2021 doi:101101/2021021021251247. :

36. Fontanet A, Autran B, Lina B, Kieny MP, Karim SSA, Sridhar D. SARSCoV-2 variants and ending the COVID-19 pandemic. Lancet. 2021. DOI: 10.1016/s0140-6736(21)00370-6

37. Ledford H. How 'killer' T cells could boost COVID immunity in face of new variants. Nature. 2021;590(7846):374-5. DOI: 10.1038/ d41586-021-00367-7

38. (CHMP), EMACFHMP. Reflection paper on the regulatory requirements for vaccines to provide protection against variant strain(s) of SARS-CoV-2. EMA/117973/2021. 23 February 2021. Disponible en http://assetscomitedebioeticaes/files/documentacion/es/cuestiones-etico-legales-rechazo-vacunas-propuestas-debate-necesariopdf 2021

39. ECDC. Updated rapid risk assessment from ECDC on the risk related to the spread of new SARS-CoV-2 variants of concern in the EU/ EEA - first update. Euro Surveill. 2021;26(3). DOI: 10.2807/15607917.Es.2021.26.3.2101211

40. (WHO). WHO. Considerations for implementing a risk-based approach to international travel in the context of COVID-19 [updated 16 December 2020; cited 19 January 2021]. . Disponible en: https:// wwwwhoint/publications/i/item/WHO-2019-nCoV-Risk-based-international-travel-20201. 2021.

41. Eaton L. Covid-19: WHO warns against "vaccine nationalism" or face further virus mutations. Bmj. 2021;372:n292. D0I: 10.1136/ bmj.n292

42. Salud OMdl. Acelerador del acceso a las herramientas contra la COVID-19. https://wwwwhoint/es/initiatives/act-accelerator Consultado el 8/04/2021. 2021.

43. Gavi. Covax vaccine roll out. https://wwwgaviorg/covax-facility Consultado el 8/04/2021. 2021. DOI:

44. Ghebreyesus TA, U. vdL. Noticias de la OMS . https://wwwwhoint/es/ news-room/commentaries/detail/a-global-pandemic-requires-aworld-effort-to-end-it-none-of-us-will-be-safe-until-everyoneis-safe Consultado el 8/04/2021. 2021. 